detected at the first possible opportunity and treated while there is still a chance of cure.

People who have had a laryngectomy need to take precautions when bathing, and specially designed stomal covers are available for those who prefer to shower. Most will have been advised to avoid deep water, boating, fishing, and swimming, though the more enterprising and daring can swim with modified snorkels and expert training. ${ }^{5}$

Eating a normal diet can also be difficult. Large tumours have often affected the pharynx or base of the tongue, and these structures are frequently resected. Myocutaneous flaps and other reconstructive techniques contribute substantially to the restoration of a reasonable food passage. Unfortunately, some patients acquire an atonic segment, and in others stenosis may develop, sometimes months after surgery. Repeated dilatation or myotomy may help but most patients spontaneously adjust the consistency of their diet and take generous amounts of fluid with meals. A few refuse to eat in public. The aroma of good food is difficult to appreciate, for the sense of smell is diminished by inevitable nasal redundancy. For some living alone, this inability to smell adequately is also a hazard. Being unable to smell smoke or gas could cost the life of the patient and possibly others. It is possible to train people who have had a laryngectomy to sniff by using their buccopharyngeal musculature to draw air into the nose, but this aspect of rehabilitation usually receives scant attention. ${ }^{67}$

Many of the problems encountered by this group of patients are far better shared. Informed support from the patient's family is vitally important, and those with supportive families reintegrate into society better and are more likely to acquire oesophageal speech. Self help support groups are invaluable and both patients and their families should be encouraged to join their local laryngectomee club-details are available from the National Association of Laryngectomy Clubs, Ground Floor, 6 Rickett Street, Fulham, SW6 1RU; telephone 071381 9993. Most importantly, all these patients should have easy access to experienced speech and language therapists who, in addition to their role in vocal rehabilitation, will be the main source of long term counselling and support.

\section{MICHAEL GLEESON}

Reader and consultant otolaryngologist PIYUSH JANI

Department of Surgery, Registrar in otolaryngology

Guy's Hospital,

London SE1 9RT

1 OPCS. Cancer Statistics. London: HMSO, 1985. (MBI 18.)

2 Gleeson MJ. Voice after laryngectomy. BMF 1992;304:2-3

3 Haughey BH, Gates GA, Arfken CL, Harvey J. Meta-analysis of second malignant tumors in head and neck cancer: the case for an endoscopic screening protocol. Ann Otol Rhinol Laryngol 1992; and neck cancer-12.

4 Terhaard CHJ, Hordijk GJ, van den Broek P, de Jong PC, Snow GB, Hilgers FJM, et al. The laryngeal cancer: a retrospective study of the Dutch Head and Neck Oncology Cooperative Group study design and general results. Clin Otolaryngol 1992;17:393-402.

5 Gray RF. Swimming after laryngectomy. Laryngoscope 1982;92:815-7.

6 Moore-Gillon V. The nose after laryngectomy. $\exists R$ Soc Med 1985;78:435-9.

7 Damste PH. Extras in rehabilitation: smelling and swimming. In: Keith RL, Darley FL, eds. Laryngectomee rehabilitation. London: Taylor and Francis; 1986:366-9.

\title{
Necrotising fasciitis
}

\author{
Be bloody, bold, and resolute
}

In view of the recent intense media attention given to necrotising fasciitis it may be opportune to examine the facts. Perhaps the most important, given the current hysteria, is that the number of laboratory reports of systemic infection with group A streptococci in England and Wales made to the Communicable Disease Surveillance Centre has not changed over the past three years. In the first 16 weeks of this year 200 blood isolates were reported, compared with 212 and 200 in the first 16 weeks of 1993 and 1992, respectively. ${ }^{1}$

The condition was first described in a specific body region by Fournier in $1883^{2}$ and as a more generalised condition by Meleney in $1924 .^{3}$ Uncommon rather than rare, necrotising fasciitis causes potentially devastating morbidity and frequently death. ${ }^{4}$

The bacteriology of necrotising fasciitis is unclear, ${ }^{56}$ in particular whether synergy is required. Meleney's original description was of a streptococcal condition, ${ }^{3}$ like the cases presented recently in the media. Later he described the synergistic form. ${ }^{7}$ No evidence exists that the recent British cases are either linked to each other or in any other way different from the many hundreds of cases reported in the medical literature. Necrotising fasciitis may simply lie towards one end of a spectrum of soft tissue infections ranging from simple cellulitis to myositis requiring amputation. ${ }^{8}$

The diagnosis is clinical. Patients are very sick with "disproportionate" pain and only minor skin changes in the early phases; "atypical cellulitis" is often diagnosed."

Microscopy of the aspirate from the subcutaneous tissue may show organisms, and imaging techniques may show infection spreading along tissue planes. The main diagnostic tool, however, is surgical exploration. The characteristic finding is of grey, oedematous fat, which strips off the underlying fascia with a sweep of the finger. Deeper changes are invariably more widespread than the skin changes. ${ }^{4}$

Shock and multiorgan failure are common, so resuscitation and general supportive measures are vital. Three specific treatments have been suggested: antibiotics, hyperbaric oxygen, and surgery. No evidence exists that antibiotics halt the infection in necrotising fasciitis and their use may tempt the surgeon to perform less mutilating but less effective surgery. Nevertheless, broad spectrum cover is routine and should specifically target anaerobes and streptococci. The action group of the Public Health Laboratory Service has endorsed immediate treatment of all suspected cases of invasive streptococcal disease with benzyl penicillin $(2.4 \mathrm{~g}$ at four hourly intervals). Clindamycin (0.6-1.2 $\mathrm{g}$ at six hourly intervals) should be considered as additional treatment in severe cases (with reductions in doses in children). ${ }^{1}$

Hyperbaric oxygen is strongly advocated by some. ${ }^{9}$ Doubts remaining over its use centre on logistic problems and lack of hard evidence as to its benefit. ${ }^{10}$ Using it would seem reasonable if it was readily available but not if the need for interhospital transfer delayed definitive surgery. 
Surgery remains the core of treatment. Although occasional reports still advocate incisional surgery (Meleney's original suggestion $\left.{ }^{3}\right),{ }^{11}$ larger series have shown that radical excisional surgery improves survival, albeit at the cost of greater final deformity ${ }^{4578}$ Skin and fat, but not usually the deep fascia, are excised. Muscle is not usually involved and amputation is not required unless this fascial barrier has been breached. The limits of surgery may be guided by microscopy but are essentially decided clinically. The aim is to perform definitive surgery, no matter how radical, at the first operation. Good quality survival has been achieved after excision of as much as $45 \%$ of a patient's surface area. In experienced centres, in early disease, aggressive surgery and antibiotics can yield death rates less than $10 \%$. Where these conditions are not met mortality may be $30-60 \%{ }^{468}$

Necrotising fasciitis has been with us for a long time; it is common enough that most hospital doctors will see a few cases yet rare enough that each new generation has to relearn the lessons of the past. Early diagnosis on clinical grounds, aggressive surgical clearance, and the full range of intensive care support can yield a low mortality and acceptable morbidity.

TIMOTHY S BURGE Registrar

JAMES D WATSON Consultant

South East Scotland Plastic Surgery Unit,

St John's Hospital,

Livingston EH54 6PP

1 Invasive group A streptococcal infections in Gloucestershire. CDR Weekly 1994;4(21):97.

2 Fournier JA. Gangrene foudroyant de la verge. Semaine Med 1883;3:345.

3 Meleney FL. Hemolytic streptococcus gangrene. Arch Surg 1924;9:31.

Ward RG, Walsh MS. Necrotizing fasciitis: 10 years' experience in a district general hospital. $B r \mathcal{F}$ Surg 1991;78:488.

5 Ledingham IMcA, Tehrani MA. Diagnosis, clinical course and treatment of acute dermal gangrene. $B r$ f Surg 1975;62:364.

6 Giuliano A, Lewis F, Hadley K, Blalsdell FW. Bacteriology of necrotizing fascitis. Am $\mathcal{f}$ Surg 1977;134:52.

7 Meleney FL. "Haemolytic streptococcus gangrene" vs "syngergistic gangrene." Surg Gynae Obstet 1933;56:847.

8 Patino JF, Castro D. Necrotizing lesions of soft tissues: a review. World f Surg 1991;15:235

9 Kindwall EP. Hyperbaric oxygen. BMf 1993;307:515-6.

10 Burge TS. Hyperbaric oxygen - still unproved in necrotising fasciitis. $B M 71993 ; 307: 936$.

11 Vassallo DJ, Lovegrove JE, Owen-Smith M. Necrotising fascitis of the leg as a complication of assallo DJ, Lovegrove JE, Owen-Smith M. Necrotising
ischiorectal abscess. F R Amy Med Corps 1993;139:63.

\section{Application of quality standards to hearing aid services}

\section{Outcome measures should be based on listeners' needs}

Recent years have seen a welcome increase in emphasis on robust outcome measures to assess the effectiveness of intervention in clinical practice. For diseases that are severe or life threatening the outcomes can be relatively simple and robust (for example, survival rates). For conditions resulting in chronic disability, however, deriving outcomes to assess quality standards is harder. Because of epidemiological evidence that hearing disability in adults is common ${ }^{1}$-and fewer than one third of candidates for hearing aids have one ${ }^{2}$-attention is now turning to the effectiveness of hearing aid services for adults ${ }^{3}$ and the assessment of the quality of the devices provided. ${ }^{4}$

Sounds Like Quality, guidelines produced by the National Committee of Professions in Audiology, suggests sensible targets for the delivery of hearing aids and rehabilitation to people with impaired hearing. Notably lacking, however, are recommendations for assessing outcome, either in terms of the ability of hearing aids to improve the understanding of speech or in terms of the extent to which the hearing aids and rehabilitation alleviate the disabilities suffered by hearing impaired people.

Discussing the assessment of hearing aids, Lyregaard has advanced two main arguments. ${ }^{4}$ Firstly, he says that the traditional electroacoustic specifications for the performance of hearing aids inadequately describe the aids' performance in everyday life, especially given the added complexity of modern techniques of signal processing. Secondly, he says that the rational application of new technology will require clinical trials that incorporate measures that are based on listeners' needs rather than laboratory measurements. Current knowledge indicates that, as well as measures of performance (such as the discrimination of speech), subjective (self reported) measures of hearing disability are needed. Although substantial advances have been made, suitable outcome measures to assess the overall and differential health gain are not yet available. Evaluation of the efficacy of current services and national decisions about future changes are impossible without them. Such measures need to be tailored for use in several circumstances: routine practice as part of ongoing audit; large scale studies of change in the NHS hearing aid services; and evaluation of new technologies. These may seem daunting requirements, yet audiology has a much better track record in developing outcome measures than many other disciplines concerned with disability.

STUART GATEHOUSE Scientist in charge

Scottish section,

MRC Institute of Hearing Research,

Glasgow Royal Infirmary,

Glasgow G31 2ER

1 Davis AC. The prevalence of hearing impairment and reported hearing disability among adults in Great Britain. Int $f$ Epidemiol 1989;18:911-7.

2 Haggard MP, Gatehouse S. Candidature for hearing aids: statistical and performance justification for a dual-component audiometric criterion. Br $\mathcal{A}$ Audiol 1993;27:303-18.

3 National Committee for Professions in Audiology. Sounds like quality: a framework for better hearing services to adults. London: NCPA, 1992.

4 Lyregaard PE. Assessment of hearing aid quality: the shape of things to come. Netherlands: Bussum, FIDA, 1992. 